\title{
HUBUNGAN DUKUNGAN KELUARGA LANSIA TERHADAP KUNJUNGAN LANSIA KE POSYANDU LANSIA DI WILAYAH KERJA PUSKESMAS KUMUN KOTA SUNGAI PENUH
}

\author{
Riris Friandi \\ Akademi Keperawatan Bina Insani Sakti \\ Email Korespondensi: endi.arbios@yahoo.com \\ Disubmit: 24 Januari 2022 Diterima: 27 Januari 2022 Diterbitkan: 02 Februari 2022 \\ DOI: https://doi.org/10.33024/mnj.v5i2.5915
}

\section{ABSTRACT: RELATIONSHIP OF ELDERLY FAMILY SUPPORT TO ELDERLY VISITS TO THE ELDERLY POSYANDU IN THE WORKING AREA OF THE KUMUN HEALTH CENTER IN SUNGAI PENUH CITY.}

Introduction: Posyandu for the elderly is a development of government policy through health services for the elderly whose implementation is through the puskesmas program by involving the role of the elderly, families, community leaders, and social organizations in its implementation. Elderly visits at the Kumun Health Center have only reached 30\% in January-June 2021 or only 580 elderly have visited the elderly posyandu.

Objective: To determine the relationship of elderly family support to elderly visits to the posyandu for the elderly in the Kumun Community Health Center in Sungai Penuh City in 2021.

Methods: The type of research used is analytic with a cross sectional approach which was carried out from September 2021 to January 2022. The population in this study were all elderly people in the Kumun Health Center Working Area, Sungai Penuh City from January to June. In 2021 there are 2,190 people with a research sample of 98 respondents. with random sampling technique. Data was collected using a questionnaire, then the data was processed and analyzed descriptively and bivariate univariate with chi-square test and correlation.

Results: The results showed that more than half (53.1\%) of respondents did not regularly visit the elderly posyandu and more than half (52\%) of respondents with low family support ( $p$-value 0.009).

Conclusion: There is a relationship between family support and elderly visits to the posyandu for the elderly. It is hoped that the puskesmas can provide health information about the benefits of visiting the elderly at the posyandu for the elderly.

Keywords: Knowledge, Attitude, Family Support, and Elderly Visits. 
INTISARI:HUBUNGAN DUKUNGAN KELUARGA LANSIA TERHADAP KUNJUNGAN LANSIA KE POSYANDU LANSIA DI WILAYAH KERJA PUSKESMAS KUMUN KOTA SUNGAI PENUH.

Pendahuluan: Posyandu lansia merupakan pengembangan dari kebijakan pemerintah melalui pelayanan kesehatan bagi lansia yang penyelenggaraannya melalui program puskesmas dengan melibatkan peran para lansia, keluarga, tokoh masyarakat, dan organisasi sosial dalam penyelenggaraannya. Kunjungan lansia di Puskesmas Kumun hanya mencapai 30\% pada bulan januari-Juni 2021 atau hanya ada sebanyak 580 lansia yang pernah berkunjung ke posyandu lansia.

Tujuan: Tujuan penelitian ini untuk mengetahui hubungan dukungan keluarga lansia terhadap kunjungan lansia ke posyandu lansia di Wilayah Kerja Puskesmas Kumun Kota Sungai Penuh Tahun 2021.

Metode: Jenis penelitian yang digunakan adalah analitik dengan pendekatan cross sectional yang dilaksanakan bulan September 2021 sampai Januari 2022. Populasi dalam penelitian adalah seluruh lansia di Wilayah Kerja Puskesmas Kumun Kota Sungai Penuh dari bulan Januari-Juni 2021 yang berjumlah 2190 orang dengan sampel penelitian sebanyak 98 responden. dengan teknik Random Sampling. Pengumpulan data dilakukan dengan kuesioner, kemudian data diolah dan dianalisis secara univariat deskriptif dan bivariat dengan uji chi-square dan korelasi.

Hasil: Hasil penelitian diperoleh lebih dari separuh $(53,1 \%)$ responden tidak rutin berkunjung ke posyandu lansia, dan lebih dari separuh (52\%) responden dengan dukungan keluarga rendah dengan ( $p$ value 0,009).

Kesimpulan: Terdapat hubungan dukungan keluarga terhadap kunjungan lansia ke posyandu lansia. Diharapkan pihak puskesmas dapat memberi informasi kesehatan tentang manfaat kunjungan lansia ke posyandu lansia.

Kata Kunci: Pengetahuan, Sikap, Dukungan Keluarga, dan Kunjungan Lansia.

\section{PENDAHULUAN}

Lansia merupakan tahap akhir dalam kehidupan manusia. Menua atau menjadi tua adalah suatu keadaan yang terjadi di dalam kehidupan manusia. Proses menua merupakan proses sepanjang hidup, tidak hanya dimulai dari suatu waktu tertentu, tetapi dimulai sejak permulaan kehidupan. Menjadi tua merupakan proses alamiah. Menua bukanlah suatu penyakit, tetapi merupakan proses yang berangsurangsur mengakibatkan perubahan yang kumulatif, merupakan proses menurunnya daya tahan tubuh dalam menghadapi ransangan dari dalam dan luar tubuh yang berakhir dengan kematian (Nugroho, 2008). Menurut Maryam, dkk (2011) klasifikasi lansia adalah (pralansia) seseorang yang berusia antara 45-59 tahun, (lansia) seseorang yang berusia 60 tahun atau lebih (lansia resiko tinggi) seseorang yang berusia 70 tahun atau lebih, (lansia potensial) lansia yang masih mampu melakukan pekerjaan dan kegiatan yang dapat menghasilkan barang atau jasa (lansia tidak potensial) lansia yang tidak berdaya mencari nafkah, sehingga hidupnya bergantung pada bantuan orang lain.

Seseorang akan menjalani perubahan fisik, mental, spiritual, 
ekonomi, dan social merupakan akibat dari proses menjadi tua secara alami. Masalah kesehatan merupakan salah satu persoalan yang sangat utama pada lanjut usia sehingga dibutuhkan bimbingan kesehatan kepada kelompok pra lanjut usia dan lanjut usia, bahkan semenjak usia dini. Masalah kesehatan yang dialami oleh lanjut usia adalah munculnya penyakit degenerative akibat proses penuaan, gangguan gizi (malnutrisi) penyakit infeksi serta masalah kesehatan gigi dan mulut (Kemenkes RI, 2019).

Penyakit terbanyak yang menghinggapi lanjut usia untuk penyakit tidak menular berdasarkan data Riskesdas tahun (2018) antara lain, masalah gizi, hipertensi, masalah mulut, diabetes mellitus, penyakit sendi, penyakit jantung, dan stroke. Dengan penyakit menularnya antara lain, ISPA, diare, dan pneumonia. Jumlah lansia dengan penyakit dimensia cenderung naik seiring dengan meningkatnya kasus penyakit tidak menular. Kondisi ini mengakibatkan lanjut usia mengalami ketergantungan akan bantuan orang lain atau bias juga perawatan jangka panjang atau long term care (Kemenkes RI, 2019).

Menurut World Population Prospect : The 2-15 Reviiouns, pada tahun 2015 terdapat 901 juta jumlah lansia yang terdiri dari jumlah populasi global. Pada tahun 20152030 jumlahnya diproyeksikan akan tumbuh sekitar $56 \%$ atau menjadi 1,4 milyar (Unites Nations, 2015). Populasi orang berusia diatas 65 tahun sedunia sekarang berada ada 617 juta orang, angka tersebut setara dengan $8,5 \%$ dari jumlah seluruh penduduk didunia. Namun demikian, sebelum tahun 2050, jumlah penddudk lanjut usia meningkat menjadi 1,6 milyar orang, setara dengan hamper $17 \%$ penduduk dunia saat itu (U.S. National Institute On Aging, 2016).

Berdasarkan Badan pusat Statistik tahun (2021) di Indonesia lansia yang usia di atas 60 tahun, dari tahun ketahun lansia di Indonesia semakin meningkat pada tahun 2019 sebanyak 87,58\% dan pada tahun 2020 sebanyak $88,22 \%$. Berdasarkan data dari Badan Pusat Statistik Provinsi Jambi tahun (2018) diketahui bahwa jumlah penduduk sebanyak 3.570.272, dari data tersebut penduduk laki-laki sebnyak 1.821.381 jiwa dan perempuan sebanyak 1.748.891 jiwa. Berdarakan usia 60 keatas pada tahun 2017 sebanyak 247.191 lansia dan pada tahun 2018 sebanyak 262.387 lansia.

Berdasarkan data yang diperoleh di Dinas Kesehatan Kota Sungai Penuh jumlah lansia dikota Sungai Penuh sebanyak 9684 orang dengan Jenis kelamin laki-laki sebanyak 4278 orang dan jenis kelamin perempuan sebanyak 5406 orang sedangkan lansia yang aktif berkunjung ke posyandu lansia Pada tahun 2019 sebanyak 5.036 (52\%). Pada tahun 2020 Jumlah lansia dikota Sungai Penuh meningkat sebanyak 10.178 orang dengan jumlah lansia berjenis kelamin laki-laki sebanyak 4501 orang dan perempuan sebanyak 5677 orang. Sedangkan jumlah lansia yg aktif berkunjung keposyandu Lansia pada tahun 2020 sebanyak 5.496 (54\%). Target pencapaian keaktifan kunjungan lansia ke posyandu berdasarkan SPM Dinas Kesehatan Kota Sungai Penuh adalah sebanyak 100 \%. (Dinas Kesehatan Kota Sungai Penuh, 2021)

Dampak dari lansia yang tidak berkunjung disebabkan oleh kurangnya informasi tentang jadwal 
pelaksanaan posyandu lansia, jarak rumah yang jauh dari posyandu lansia, sarana dan prasarana yang kurang baik, adanya fasilitas lain yang diberikan pemerintah seperti asuransi kesehatan, sikap dan perilaku tertutup terhadap posyandu lansia (Juniardi F, 2012). Salah satu upaya yang dilaksanakan untuk meningkatkan kesejahteraan lansia adalah program posyandu lansia, sebagai salah satu program puskesmas melalui kegiatan peran serta masyarakat yang ditujukan pada masyarakat setempat, khususnya lansia. Pelayanan kesehatan di posyandu lansia meliputi pemeriksaan kesehatan fisik dan mental emosional yang dicatat dan dipantau dengan Kartu Menuju Sehat (KMS) untuk mengetahui lebih awal penyakit yang diderita atau ancaman masalah kesehatan yang dihadapi (Ningsih, 2014).

Berdasarkan penelitian yang dilakukan oleh Amaral A dkk (2017) adapun fenomena yang terjadi pada posyandu lansia adalah menunjukkan fakta yang berbeda, posyandu lansia hanya ramai diawal pendiriannya saja, selanjutnya lansia yang memanfaatan posyandu semakin berkurang. Berdasarkan Departemen Kesehatan RI (2010) keaktifan lansia keposyandu lansia dapat dikatakan kehadirannya yang baik atau aktif dalam mengikuti kegiatan diposyandu lansia apabila frekuensi kehadiran $>6$ kali per tahun, sedangkan dikatakan kehadirannya yang buruk atau tidak aktif apabila frekuensi kehadirannya $<6$ kali per tahun.

Kunjungan keposyandu lansia adalah datangnya lansia ke posyandu lansia untuk mendapatkan pelayanan kesehatan. Ada beberapa faktor yang mempengaruhi pemanfaatan posyandu lansia antara lain umur, jenis kelamin, pendidikan, pekerjaan, pengetahuan, petugas kesehatan, pelayanan kesehatan, sikap petugas, dukungan keluarga (Sulistyorini, 2010).

Menurut Green perilaku yang berhubungan dengan kesehatan dipengaruhi oleh dua faktor pokok yakni perilaku dan faktor diluar perilaku kemudian dibentuk oleh tiga faktor antara lain: 1) faktor predisposisi meliputi umur, jenis kelamin, pendidikan, pekerjaan, pengetahuan, sikap. 2) faktor pemungkin meliputi kualitas pelayanan, jarak tempuh, sikap petugas 3) faktor penguat meliputi petugas atau kader, keluarga. Dari semua faktor tersebut terdapat beberapa faktor yang lebih mempengaruhi kunjungan lansia keposyandu lansia yaitu pengetahuan, sikap, dan dukungan keluarga lansia (Kurniasari, 2013).

Dukungan keluarga adalah sebuah proses yang terjadi sepanjang masa kehidupan. Sifat dan jenis dukungan berbeda dalam berbagai tahap-tahap siklus kehidupan. Dukungan keluarga dapat berupa dukungan social internal, seperti dukungan dari suami, istri, atau dukungan dari saudara kandung dan dapat juga berupa dukungan keluarga eksternal bagi keluarga inti. Sebagai akibatnya, hal ini meningkatkan kesehatan dan adaptasi keluarga (Friedman, 2010).

Berdasarkan penelitian yang dilakukan oleh Role dkk (2017) dengan judul penelitian "Hubungan Tingkat Pengetahuan Manfaat Posyandu Lansia dengan Keaktifan Lansia di Posyandu Lansia Kecamatan Lowokwaru Kota Malang". Didapatkan hasil bahwa dengan analisis pearson product Moment menunjukkan $p$ value $0,026<0,05$, artinya ada 
hubungan tingkat pengetahuan manfaat posyandu lansia dengan keaktifan lansia di posyandu lansia.

Penelitian yang dilakukan oleh Nadirah dkk (2020) dengan judul penelitian (Pengetahuan dan Sikap terhadap Pemanfaatan Kunjungan Posyandu Lansia". Didapatkan hasil bahwa dengan variabel pengetahuan $p$ value 0,003 dan variable sikap $p$ value 0,002 disimpulkan bahwa ada hubungan pengetahuan dan sikap terhadap pemanfaatan kunjungan diposyandu lansia.

Berdasarkan penelitian yang dilakukan oleh Gestinarwati (2016) dengan judul peneitian "Hubungan Dukungan Keluarga dengan Kunjungan Lansia ke Posyandu". Dengan didapatkan hasil bahwa $p$ value 0,000 maka <a $(0,05)$ artinya Ho ditolak, sehingga dapat disimpulkan bahwa ada hubungan yang signifikan antara dukungan keluarga dengan kunjungan lansia ke posyandu lansia.

Menurut Puskesmas Kumun, jumlah lansia diwilayah kerja Puskesmas Kumun pda tahun 2019 sebanyak 1902 orang, tahun 2020 sebanyak 1982 orang dan pada tahun 2021 jumlah lansia sebanyak 2190 orang. Jumlah posyandu lansia yang ada di Wilayah Kerja Puskesmas Kumun Kota Sungai Penuh sebanyak 8 posyandu, jumlah lansia yang aktif berkunjung ke posyandu lansia pada tahun 2019 sebanyak 789 orang(42\%). Pada tahun 2020 sebanyak 825 orang (43\%) .Lansia yang aktif berkunjung keposyandu Lansia diwilayah kerja Puskesmas Pondok Tinggi Kota Sungai Penuh pada tahun 2021 dari bulan januari-juni sebanyak 551 orang (27\%). (Puskesmas Kumun Kota Sungai Penuh, 2021).

Berdasarkan hasil survey yang dilakukan di rumah-rumah Wilayah Kerja Puskesmas Kumun Kota Sungai
Penuh pada tanggal 29 September 2021, dari 10 lanjut usia yang belum pernah menjadi responden di dapatkan 6 lansia belum pernah keposyandu, (60\%) lansia mengatakan kurangnya pengetahuan mengenai posyandu lansia, tidak mengetahui kapan jadwal kegiatan posyandu, dan juga keluarga tidak mendukung untuk keposyandu lansia karena pergi ke posyandu cuman habis-habisin duit saja. 4 lansia pernah keposyandu, (40\%) lansia mengatakan kalau keluarga mengingatkan tentang jadwal kegiatan posyandu dan menganggap datang ke posyandu lansia hanya saat merasakan sakit saja.

Berdasarkan wawancara pada tanggal 29 September 2021 dengan petugas posyandu lansia diketahui bahwa lansia belum mengetahui tujuan dan manfaat diadakannya posyandu lansia. Selain itu kunjungan ke posyandu masih rendah dikarenakan kondisi fisik dari lansia yang tidak memungkinkan untuk datang pada saat pelaksanaan posyandu. Menurut catatan kunjungan lansia di posyandu hanya 42,02\% lansia yang hadir kegiatan posyandu dalam satu tahun, Adapun target persentase lansia yang mendapatkan pelayanan kesehatan diposyandu Lansia berdasarkan SPM Dinkes Kota Sungai Penuh yaitu sebanyak 100,00\%.

\section{METODE PENELITIAN.}

Jenis penelitian ini bersifat analitik dengan pendekatan cross sectional study, yaitu variabel bebas dan terikat diukur pada saat yang sama, pada waktu penelitian berlangsung dimana hasilnya dapat memberikan gambaran tentang hubungan antara dua variabel 
penelitian tersebut (Notoadmodjo, 2012).

Variabel independent dalam penelitian ini adalah dukungan keluarga, sedangkan variable dependen adalah kunjungan lansia ke posyandu lansia di Wilayah Kerja Puskesmas Kumun Kota Sungai Penuh Tahun 2021.

Populasi adalah keseluruhan objek penelitian atau objek penelitian yang diteliti (Notoadmodjo, 2012). Populasi dalam penelitian adalah seluruh lansia di Wilayah Kerja Puskesmas Kumun Kota Sungai Penuh tahun 2021 yang berjumlah 2190 orang. Mengetahui besar sampel yang diambil dalam penelitian ini adalah menggunakan metode perhitungan sampel minimal menggunakan rumus Notoadmodjo (2010) sebagai berikut :

$$
n=\frac{N}{1+N(d)^{2}}
$$

Keterangan:

$\mathrm{n}=$ Ukuran populasi.

$\mathrm{d}=$ Tingkat kepercayaan / ketetapan yang diinginkan $90 \%(0,1)$.

$\mathrm{N}=$ Jumlah populasi.

Sampel penelitian yang dilakukan sebanyak 98 sampel. Teknik pengambilan sampel yang digunakan dalam penelitian ini adalah menggunakan teknik Random Sampling adalah jenis pengambilan sampel probability dimana setiap orang disuruh populasi target memiliki kesempatan yang sama untuk dipilih (Hidayat, 2011). Untuk menentukan sampel dengan cara dilotre dari 9 Desa/Kelurahan yang telah terkoordinasi dengan Kader.

Adapun etika penelitian menurut Hidayat (2011), dimana etika penelitian yang harus diperhatikan adalah sebagai berikut: Informed consent diberikan kepada responden sebelum melakukan penelitian. Agar responden mengerti maksud dan tujuan penelitian serta mengetahui dampak dan manfaatnya. Jika responden bersedia, maka responden harus menandatangani lembar persetujuan. Adapun kerahasiaan semua informasi yang telah dikumpulkan dijamin kerahasiaannya oleh peneliti, hanya kelompok data tertentu yang akan dilaporkan pada hasil riset. Peneliti menejelaskan bahwa semua data dan informasi yang telah diberikan oleh responden akan dijaga dan tidak disebarluaskan pada orang lain.

Teknik pengumpulan data peneliti peroleh dengan mengumpulkan data primer dan data sekunder: dengan menggunakan kuesioner, informed consent dan wawancara. Kuesioner merupakan sejumlah pertanyaan tertulis yang digunakan untuk memperoleh informasi dari responden. Kuesioner yang digunakan adalah pertanyaan terstruktur untuk mengambil data kunujungan lansia ke posyandu lansia. Data penunjang yang diperoleh dari Puskesmas Pondok Tinggi Kota Sungai Penuh yang berupa laporan tahunan kunjungan lansia ke posyandu lansia, KMS, dan hal-hal yang berhubungan dengan penelitian yang diperoleh dari rekapitulasi di Puskesmas Kumun Kota Sungai Penuh.

Pengolahan data pada penelitian ini mulai dengan (Editing) pengecekan dan perbaikan isian kuisioner dilanjutkan dengan pemberian code setelah semua data diedit atau disunting, selanjutnya dilakukan pengkodean atau coding, yakni mengubah data berbentuk kalimat atau huruf menjadi data angka atau bilangan. Selanjutnya dengan penskoringan dimana peneliti memberi skor untuk masing masing pertanyaan dan selanjutnya memasukkan data yang sudah 
dilakukan pengkodean kedalam program komputer SPSS dan dilanjutkan Tabulating atau Memasukkan data dari hasil penelitian ke dalam tabel-tabel sesuai kriteria dan terkahir di cleaning. kegiatan pengecekan kembali untuk melihat kemungkinan-kemungkinan adanya kesalahan-kesalahan kode, kemudian dilakukan pembentulan atau koreksi.

Teknik analisa data dalam penelitian ini dengan menggunakan Analisa univariat yang dilakukan secara deskriptif atau melihat gambaran distribusi frekuensi masingmasing variabel yaitu Dukungan keluarga analisa bivariat untuk menguji hipotesa apakah ada hubungan dukungan keluarga lansia terhadap kunjungan lansia ke posyandu lansia pada tahun 2021. Tujuan analisa bivariat ini adalah untuk melihat hubungan variabel dependen dan idependen dengan menggunakan uji chi-square pada pengolahan data dengan program SPSS, dengan derajat kepercayaan $95 \%$ $(\mathrm{a}=0,05)$. dengan hasil analisa penelitian ini menunjukan hubungan yang bermakna dimana nilai $\mathrm{p}$ value $<$ 0,09 . Uji validitas penelitian ini dilakukan di Puskesmas Pondok Tinggi Kota Sungai Penuh dan Penguji realibilitas di mulai dengan menguji validitas terebih dahulu. Jadi jika pertanyaan tidak valid, maka pertanyaan tersebut dibuang atau diperbaiki. Hasil dari uji reabilitas tingkat dukungan keluarga dalam penelitian ini dengan Cronbach's Alpha 0,794 , sedangkan uji validitas dengan 20 butir pernyataan dengan nilai 0,510 .

\section{HASILPENELITIAN DAN PEMBAHASAN Analisis Univariat}

Tabel 1. Distribusi frekuensi kunjungan lansia ke posyandu lansia di Wilayah Kerja Puskesmas Kumun Kota Sungai Penuh.

\begin{tabular}{ccc}
\hline Kunjungan lansia & Frekuensi & Persentase $\%$ \\
\hline Tidak Rutin & 52 & 53,1 \\
\hline Rutin & 46 & 46,9 \\
\hline Total & 98 & 100,0 \\
\hline \hline Dukungan Keluarga & Frekuensi & Persentase $\%$ \\
\hline Rendah & 51 & 52 \\
\hline Tinggi & 47 & 48 \\
\hline Total & 98 & 100,0 \\
\hline
\end{tabular}

Tabel diatas menunjukkan bahwa dari 98 responden terdapat sebagian besar responden yaitu 52 responden $(53,1 \%)$ kunjungan tidak rutin dan 46 responden (46,9\%) kunjungan rutin di Wilayah Kerja
Puskesmas Kumun Kota Sungai Penuh Tahun 2021. Tabel di atas juga menunjukkan bahwa dari 98 responden sebagian besar yaitu 51 responden (52\%) dukungan keluarga rendah dan 47 responden (48\%) 
dukungan keluarga tinggi di Wilayah Kerja Puskesmas Kumun Kota Sungai Penuh Tahun 2021.

\section{Analisa Bivariat}

Tabel 2. Hubungan dukungan keluarga lansia terhadap kunjungan lansia ke posyandu lansia di Wilayah Kerja Puskesmas Pondok Tinggi Kota Sungai Penuh

\begin{tabular}{|c|c|c|c|c|c|c|c|c|}
\hline \multirow{3}{*}{$\begin{array}{c}\text { Dukungan } \\
\text { Keluarga }\end{array}$} & \multicolumn{4}{|c|}{ Kunjungan Lansia } & \multirow{2}{*}{\multicolumn{2}{|c|}{ Jumlah }} & \multirow{3}{*}{$\begin{array}{c}P \\
\text { Value }\end{array}$} & \multirow{2}{*}{ OR } \\
\hline & \multicolumn{2}{|c|}{ Tdk Rutin } & \multicolumn{2}{|c|}{ Rutin } & & & & \\
\hline & $f$ & $\%$ & $\mathrm{~F}$ & $\%$ & $F$ & $\%$ & & \\
\hline Rendah & 34 & 65,4 & 17 & 37 & 51 & 100 & & \\
\hline Tinggi & 18 & 34,6 & 29 & 63 & 47 & 100 & 009 & , LLL \\
\hline Total & 52 & & 46 & & 98 & 100 & & \\
\hline
\end{tabular}

Tabel diatas menunjukan bahwa responden yang memiliki dukungan keluarga rendah dengan kunjungan lansia tidak rutin yaitu 34 responden $(65,4 \%)$ dibandingkan dengan kebiasaan dukungan keluarga rendah kunjungan lansia rutin yaitu 17 responden (37\%). Sedangkan yang memiliki dukungan keluarga tinggi dengan kunjungan lansia tidak rutin yaitu 18 responden $(34,6 \%)$ dibandingkan dengan dukungan lansia tinggi dengan kunjungan lansia rutin yaitu 29 responden $(63 \%)$. Berdasarkan hasil analisis statistik dengan uji chi square diperoleh $\mathrm{p}$ value 0,009 dengan

\section{PEMBAHASAN}

Analisa Univariat

Berdasarkan hasil penelitian diperoleh hasil lebih separuh $(53,1 \%)$ responden tidak rutin ke posyandu lansia Kumun Kota Sungai Penuh Tahun 2021.

Penelitian ini sejalan dengan penelitian yang dilakukan oleh Prestya dkk (2019) dengan judul penelitian "Gambaran Keaktifan Lansia Mengikuti Posyandu Lansia". derajat kemaknaan $95 \%(\propto=0,05)$. Hal ini dapat disimpulkan bahwa ada Hubungan dukungan keluarga lansia terhadap kunjungan lansia ke posyandu lansia di Wilayah Kerja Puskesmas Pondok Tinggi Kota Sungai Penuh Tahun 2021. Kemudian diperoleh nilai Odds Ratio $=3,222$. artinya dukungan keluarga mempunyai peluang lebih besar menyebabkan dukungan keluarga rendah dibanding kunjungan lansia rutin. Sehingga lansia harus diberikan penyuluhan yang baik tentang dukungan lansia pada lansia.

Didapatkan hasil bahwa lebih dari separuh sebanyak $(63,9 \%)$ responden lansia yang tidak aktif ke posyandu lansia sedangkan yang aktif sebanyak $(36,1 \%)$ responden.

Posyandu merupakan langkah yang cukup strategis dalam rangka pengembangan kualitas sumber daya manusia bangsa Indonesia agar dapat membangun dan menolong dirinya sendiri, sehingga perlu ditingkatkan pembinaannya. Untuk meningkatkan 
pembinaan posyandu sebagai pelayanan dan kesehatan yang dikelola untuk dan oleh masyarakat dengan dukungan pelayanan teknis dari petugas perlu ditumbuh kembangkan.

Berdasarkan Departemen Kesehatan RI (2010) keaktifan lansia keposyandu lansia dapat dikatakan kehadirannya yang baik atau aktif dalam mengikuti kegiatan diposyandu lansia apabila frekuensi kehadiran $>6$ kali per tahun, sedangkan dikatakan kehadirannya yang buruk atau tidak aktif apabila frekuensi kehadirannya < 6 kali per tahun. Kunjungan keposyandu lansia adalah datangnya lansia ke posyandu lansia untuk mendapatkan pelayanan kesehatan. Ada beberapa faktor yang mempengaruhi pemanfaatan posyandu lansia antara lain umur, jenis kelamin, pendidikan, pekerjaan, pengetahuan, petugas kesehatan, pelayanan kesehatan, sikap petugas, dukungan keluarga (Sulistyorini, 2010).

Menurut asumsi penelitian responden yang tidak rutin ke posyandu lansia disebabkan oleh ketidaktahuan lansia mengenai posyandu lansia dimana ketika ditanya mengenai posyandu, sebaigian lansia tidak mengetahui apa kegiatan dan maksud dari posyandu lansia. Semakin bertambahnya umur, maka semakin berkurangnya pengetahuan lansia.

Berdasarkan hasil penelitian diperoleh hasil lebih separuh (52\%) responden dengan dukungan keluarga rendah tentang kunjungan lansia ke posyandu lansia di Wilayah Kerja Puskesmas Kumun Kota Sungai Penuh Tahun 2021.

Penelitian ini sejalan dengan penelitian yang dilakukan oleh Handayani \& Wahyuni (2012) dengan judul peneitian "Hubungan Dukungan
Keluarga dengan Kepatuhan Lansia dalam Mengikuti Posyandu Lansia di Posyandu Lansia Jetis Desa Krajan Kecamatan Weru Kabupaten Sukoharjo". Dengan didapatkan hasil bahwa dukungan keluarga lansia di posyandu lansia rendah sebanyak $(60 \%)$ responden dan tinggi sebanyak (40\%) responden.

Dukungan keluarga adalah sebuah proses yang terjadi sepanjang masa kehidupan. Sifat dan jenis dukungan berbeda dalam berbagai tahap-tahap siklus kehidupan. Dukungan keluarga dapat berupa dukungan social internal, seperti dukungan dari suami, istri, atau dukungan dari saudara kandung dan dapat juga berupa dukungan keluarga eksternal bagi keluarga inti. Sebagai akibatnya, hal ini meningkatkan kesehatan dan adaptasi keluarga (Friedman, 2010).

Berdasarkan asumsi penelitian dukungan keluarga memiliki peran penting terhadap lansia dalam pemanfaatan posyandu oleh lansia, kalau tidak ada dukungan dari keluarga maka secara tidak langsung intensitas kunjungan lansia ke posyandu akan semakin berkurang. Bentuk dukungan keluarga yang rendah yaitu keluarga tidak mengetahui, menyetujui atau mendukung lansia agar berkunjung ke posyandu lansia. Dengan tidak adanya dukungan dari keluarga maka para lansia akan tidak jadi datang ke posyandu apalagi bagi lansia yang tidak mampu lagi berjalan sendiri untuk datang ke posyandu. Begitupun sebaliknya dengan adanya dukungan dari keluarga maka secara tidak langsung keluarga tersebut memiliki peran penting untuk meningkatkan intensitas kunjungan lansia ke posyandu. Hal ini bisa dilihat bahwa sebagian besar jawaban responden 
menjawab pada kuesioner sikap lansia poin ke 6 dengan dukungan emosional yaitu keluarga menghiraukan kondisi kesehatan bapak/ibu ketika sedang sakit sehingga tidak bisa mengikuti posyandu lansia.

\section{Analisa Bivariat}

Berdasarkan penelitian diperoleh hasil proporsi responden dengan kunjungan lansia yang tidak rutin lebih banyak dengan dukungan keluarga yang rendah yaitu lebih dari separuh sebanyak (65,4\%) dibandingkan dengan kunjungan lansia yang rutin dengan dukungan keluarga yang tinggi yaitu lebih dari separuh sebanyak (63\%). Hasil uji statistic (Chi Square) diperoleh nilai $p=0.009$ $(p<0.05)$, berarti terdapat hubungan dukungan keluarga terhadap kunjungan lansia ke posyandu lansia di Wilayah Kerja Puskesmas Kumun Kota Sungai Penuh Tahun 2021.

Berdasarkan penelitian yang dilakukan oleh Gestinarwati (2016) dengan judul peneitian "Hubungan Dukungan Keluarga dengan Kunjungan Lansia ke Posyandu". Dengan didapatkan hasil bahwa $p$ value 0,000 maka <a $(0,05)$ artinya Ho ditolak, sehingga dapat disimpulkan bahwa ada hubungan yang signifikan antara dukungan keluarga dengan kunjungan lansia ke posyandu lansia.

Friedman 1998 dalam Murniasih (2017) menyatakan dukungan keluarga adalah sikap, tindakan dan penerimaan keluarga terhadap anggotanya. Anggota keluarga dipandang sebagai bagian yang tidak terpisahkan dalam lingkungan keluarga. Anggota keluarga memandang bahwa orang yang bersifat mendukung selalu sifat memberika pertolongan dan bantuan jika diperlukan.
Dukungan keluarga adalah sebuah proses yang terjadi sepanjang masa kehidupan. Sifat dan jenis dukungan berbeda dalam berbagai tahap-tahap siklus kehidupan. Dukungan keluarga dapat berupa dukungan social internal, seperti dukungan dari suami, istri, atau dukungan dari saudara kandung dan dapat juga berupa dukungan keluarga eksternal bagi keluarga inti. Sebagai akibatnya, hal ini meningkatkan kesehatan dan adaptasi keluarga (Friedman, 2010).

Menurut asumsi penelitian bahwa dukungan keluarga memiliki peran penting terhadap lansia dalam pemanfaatan posyandu oleh lansia. Kalau tidak ada dukungan keluarga maka secara tidak langsung intensitas kunjungan lansia ke posyandu akan semakin berkurang, dengan tidak adanya dukungan dari keluarga maka para lansia akan tidak jadi dating ke posyandu apalagi bagi lansia yang tidak mampu lagi berjalan sendiri untuk dating ke posyandu.upaya yang dilakukan untuk mengantisipasi permasalahan ini adalah dengan memberikan arahan dan pemahaman kepada anggota keluarga betapa pentingnya lansia dating ke posyandu untuk memantau status kesehatan lansia setiap bulannya. Sehingga dapat mendeteksi secara dini gangguan kesehatan dan dapat meningkatkan derajat kesehatan dan usia harapan hidup lansia tersebut.

\section{KESIMPULAN}

Berdasarkan hasil penelitian dan pembahasan yang telah dilakukan maka dapat ditarik kesimpulan sebagai berikut : Lebih dari separuh $(53,1 \%)$ kunjungan lansia ke posyandu lansia, lebih dari separuh $(52,1 \%)$ dukungan keluaraga tentang 
kunjungan lansia, terdapat hubungan dukungan keluarga terhadap kunjungan lansia ke posyandu lansia di Wilayah Kerja Puskesmas Kumun Kota Sungai Penuh Tahun 2021. Dan disarankan kepada perawat puskesmas untuk meningkatkan kualitas pelayanan kesehatan lansia sehingga dapat meningkatkan kunjungan lansia ke posyandu lansia.

\section{DAFTAR PUSTAKA}

Admin. (2010). Hubungan Kondisi Fisik RTT Lansia Terhadap Kondisi Sosial Lansia Di RW 03 RT 05 Kelurahan Tegalsari Kecamatan Candisari.

http://eprints.undip.ac.id.

Diperoleh pada tanggal 23 Mei 2021.

Alhidayati. (2013). Faktor-Faktor yang Berhubungan dengan Perilaku Kunjungan Lansia ke Posyandu Lansia di Wilayah Kerja Puskesmas Kampar Kabupaten Kampar Tahun 2013. Jurnal Kesehatan Komunitas, Vol. 2, No. 5.

Ali, Z. (2010). Pengantar Keperawatan Keluarga. Jakarta : EGC

Amaral, A, Wiyono, J, \& Candawati, E. (2017). Analisis Faktor Kehadiran Lansia dalam Mengikuti Posyandu di Desa Pagersari Kecamatan Ngantang Kabupaten Malang. Jurnal Keperawatan. Vol 2, No 2.

Azwar, S. (2005). Sikap Manusia, Teori dan Pengukurannya. Yogyakarta : Pustaka Belajar.

Badan Pusat Statistik. (2021). Statistik Penduduk Lanjut Usia 2021. Badan Pusat Statistik.

Depkes RI. (2013). Pedoman Pembinaan Kesehatan Usia Lanjut Bagi PetugasKesehatan II. Direktorat Jendral Pembinaan
Kesehatan Masyarakat. Diakses pada tanggal 02 Juni 2021.

Dinas Kesehatan Kota Sungai Penuh. (2021). Data Kunjungan Lansia Ke Posyandu Lansia Tahun 2021.

Erpandi. (2014). Posyandu Lansia. Jakarta : EGC.

Friedman. (2013). Keperawatan Keluarga. Jakarta : EGC.

Friedman \& Marilyn M. (2010). Buku Ajar Keperawatan Keluarga : Riset, Teori, dan Praktek Edisi 5. Jakarta : EGC.

Gestinarwati, A, Ilyas, H \& Manurung, I. (2016). Hubungan Dukungan Keluarga dengan Kunjungan Lansia ke Posyandu. Jurnal Keperawatan. Vol 12, No. 2.

Handayani \& Wahyuni. (2012). Hubungan Dukungan Keluarga dengan Kepatuhan Lansia dalam Mengikuti Posyandu Lansia di Posyandu Lansia Jetis Desa Krajan Kecamatan Weru Kabupaten Sukoharjo.

Hidayat, A. (2011). Metode Penelitian Keperawatan dan Teknik Analisis Data. Jakarta : Salemba Medika.

Ismawati dkk. (2010). Posyandu Desa Siaga. Yogjakarta: Nuha Medika.

Juniardi, F. (2012). Faktor-Faktor yang Mempengaruhi Rendahnya Kunjungan Lansia ke Posyandu Lansia di puskesmas Batang beruh Kecamatan Sidikarang Kabupaen Dairi.

Kementrian Kesehatan RI. (2012). Buletin Jendela Data dan Informasi Kesehatan Topik Utama Gambaran Kesehatan Usia Lanjut di Indonesia. Pusat Data dan Informasi Kementrian Kesehatan RI.

Kementrian Kesehatan RI. (2019). Analisa Lansia di Indonesia. Jakarta : Pusat Data dan Informasi Kementrian Kesehatan 
RI.

Konas Lansia. (2010). Pedoman Pelaksanaan Posyandu Lansia. Jakarta : EGC.

Kurniasari. (2013). Faktor-Faktor yang Berhubungan Dengan Pemanfaatan Pelayanan Pobindu Lansia di Wilayah Kerja Puskesmas Pasar Rebo.

Lestari, Titik. (2015). Kumpulan Teori Untuk Kajian Pustaka Penelitian Kesehatan. Yogyakarta : Nuha Medika.

Maryam, R, Siti, dkk. (2011). Mengenal Usia Lanjut dan Perawatannya. Jakarta : Salemba Medika.

Mubaraq, Wahit Iqbal. (2011). Promosi kesehatan untuk kebidanan. Jakarta : Salemba Medika.

Murniasih, Erni. (2017). Hubungan Dukungan Keluarga Dengan Tingkat Kecemasan Akibat Hospitalisasi Pada Anak Usia Pra Sekolah Di Bangsal 1 RSUP Dr. Soejarwadi Tirtonegoro Klaten. Jurnal Kesehatan Surya Medika Yogjakarta.

Nadirah, Indrawati, \& Heriyati. (2020). Pengetahuan dan Sikap Terhadap Pemanfaatan Kunjungan Posyandu Lansia. Jurnal Keperawatan Profesional.

Ningsih. (2014). Studi Lomprasi Metode Permainan Monopoli dan Ceramah Terhadap Pengetahuan dan Sikap Tentang Kesehatan Reproduksi pada Remaja Dengan Pendejatan Planned Behaviour Theory', Tesis. Surabaya : Universitas Airlangga.

Notoatmodjo. (2010). Kesehatan Masyarakat : Ilmu dan Seni. Jakarta :Rineka Cipta

Notoatmodjo. (2012). Metodologi Penelitian Kesehatan. Jakarta : PT Rineka Cipta.

Nubatonis, R. (2015). Hubungan Perilaku Lansia Dengan Kejadian
Hipertensi di Puskesmas Ngelok Kabupaten Blitar; 83.

Nugroho, W. (2012). Keperawatan Gerontik dan Geriatrik Edisi 3. Jakarta:EGC

Padila. (2013). Asuhan Keperawatan Penyakit Dalam. Yogjakarta: Nuha Medika

Puskesmas Pondok Tinggi Kota Sungai Penuh. (2021). Data Jumlah Cakupam Layanan Lanjut Usia.

Riset Kesehatan Dasar. (2018). Hasil Utama Riset Kesehatan Dasar 2018.http://www.kemkes.go.id . Diakses tanggal 10 mei 2021.

Role, A. C, Harianto, $T \&$ Ardiyani, $M$. V. (2017). Hubungan Tingkat Pengetahuan Manfaat Posyandu Lansia dengan Keaktifan Lansia di Posyandu Lansia Kecamatan Lowokwaru Kota Malang. Jurnal Keperawatan. Vol 2, No. 2.

Santrock, J. (2012). Adolescence 15nd ed. USA: McGraw-Hill Education.

Sulistyorini. Dkk. (2010). Posyandu Desa Siaga. Cetakan 1. Yogjakarta : MedikalBook.

Sunaryo, Rahayu Wijayanti, Maisje Marlyn kuhu, taat sumedi, esti dwi widayanti, ulfah agus sukrillah, sugeng riyadi, ani kuswati. (2016). Asuhan Keperawatan Gerontik (1st ed.; C. Putri, Ed.). Yogyakarta; CV. Andi Offset.

United Nation. (2015). World Population Prospect, the 2015 revision.

Wanwan, A \& Dewi, M. (2010). Teori dan Pengukuran Pengetahuan, Sikap, dan Perilaku Manusia. Yogyakarta : Nuha Medika.

Yusra, Aini. (2011). Hubungan Dukungan Keluarga Dengan Kualitas HidupPasien Diabetes Melitus Tipe 2 Di Poliklinik Penyakit Dalam Rumah Sakit Umum Fatmawati 
Jakarta.lontar.ui=digital $/ 2028$ 0162-T\%20Aini\%Yusra.pdf.

Pengetahuan dan Sikap Tentang Cuci Tangan Pakai Sabun (Ctps) Pada Siswa SDN Batuah I dan Batuah III Pagatan.

https://ppjp.ulm.ac.id/journal/inde x.php/berkalakesehatan/article/view/660/0 Sunaryo. (2004). Psikologi Untuk Keperawatan. Jakarta: EGC

Sursilah, ilah. (2010). Pencegahan Infeksi dalam Pencegahan Kebidanan. Yogyakarta: Dee Publish

Susanto. (2007). Metodologi Penelitian: Jakarta: UI
Wirawan, I. Made C. (2013). Kata dokter. Jakarta Selatan: Panda Media

Yulrina, dkk. (2014). Panduan Lengkap Keterampilan Dasar Kebidanan I. Yogyakarta: Deepublish 